\title{
A New Dawn in ODOAN
}

Prof Dr Rabindra Man Shrestha

Chief Editor, OJN; President, ODOAN

The phrase 'new dawn' has been used in the titles of many musical, cinematic, and literary contexts. In 1999, Linda Perry sang a tuneful song 'new dawn' which was resung by Celine Dion in 2007. Later in 2008, Libera released an album by the name 'new dawn' featuring popular songs. New dawn (Peau neuve; in French) is a French drama film directed by Émilie Deleuze, which was screened in 1999 Cannes Film Festival. In 2003, a science fiction story collection 'A new dawn' by Robert Campbell was published. Later in 2014, John Miller authored a novel by the same name as a Star Wars series. Many leading newspapers are published in the same title in many countries like Fiji, Liberia, Pakistan, Turkey (Yeni Safak; in Turkish).

'New dawn' refers to the first light of the day; it also refers to an era when a new leadership resumes office. Presently, Orthodontic \& Dentofacial Orthopedic Association of Nepal (ODOAN) is in the stage of new dawn; which is now headed by new executive committee. The time has come when many aspirants bid their candidacy to work for the profession through their association. As usual, there are many opportunities and challenges when any new responsibilities come on the way. Responsibilities are the task to achieve the set goals and duties to fulfill the objectives.

ODOAN is the professional organization of qualified orthodontists in Nepal, established and registered for the rights and welfare of specialist orthodontists. A specialist is the qualified medical professional with masteral degree or equivalent in a specialized subject awarded by the recognized university in addition to basic bachelor level BDS or equivalent degree. Medical council provides specialty registration certificate to practice specialty discipline upon accomplishment of special licensing examination.

As stated in its articles, the objectives of ODOAN are: 1. To work for the rights and welfare of the Nepalese orthodontists, actively help fellow members in resolving professional hurdles and problems. 2. To conduct public awareness program on orthodontic health and education, and aware the public regarding modern and scientific orthodontic therapy. 3. To extend necessary assistance to Nepal Government for the improvement of orthodontic health service. 4. To provide necessary consultation, advice, and suggestion to the government and other organizations in the related field. 5. To suggest concerned authority for the capacity building of orthodontic specialists in order to upgrade and improve the contemporary orthodontic services and facilities. 6. To organize various research, training, workshop, seminar, conference etc time-to-time in the field of orthodontics. 7. To contribute in controlling the unauthorized and illegal practice in the specialized field of orthodontics, and to assist the government and related authorities for this purpose. 8. To build relation and acquire membership of national and international government, non-government agencies and organizations related to orthodontics (unofficial translations of a part of ODOAN by-laws).

In executing the set objectives; ODOAN has so far been successful in organizing the conferences, continuing education programs, training programs and publish scientific journals. ODOAN has tried to build professional relation with national dental association, had joint programs with other societies, and acquired membership of major international orthodontic organizations.

How successful is ODOAN in achieving its goals? Are the above mentioned indicators are ample to prove the office bearers as triumphant? Measure of success and failure are the assumptions which are subject to individual perceptions. However one thing is true; ODOAN has not yet stepped in to some of its agendas. 
Ideally, ODOAN should work for the rights of its fellow members and be asked for its support in resolving professional problems. Here the concern is; are the orthodontists aware about their rights. As per the provisions of the regulatory body; the registered specialists are entitled to practice their specialty discipline without hindrance, right to use title and description of the qualification, appointment in public and private hospitals, right to prescribe \&/or dispense medicine (appliance; in case of orthodontics), right to charge fee and other expenses, and right to issue health -related certificates.

The specialist practitioner's rights are in stake if any of the above mentioned provisions are hindered; or when any non-specialists are enjoying those specialized privileges. Here the concern is; how is the boundary between various levels are demarcated? The specific tasks to be rendered by a specific level are clearly mentioned in the objectives of respective curriculum. Clinical practice by less-than-qualified personnel is punishable by law and against the consumer's rights. As per its objectives, ODOAN attempts to help regulatory bodies in controling the unauthorized and illegal practice in the specialized field of orthodontics. The task is underway and the operation continues.

'Operation The Dawn' (also known as Operation Al-Fajr) is the joint US-Iraqi offensive against insurgent stronghold of Fallujah during Iraq War in 2004. Similarly 'Operation New Dawn' is the military operation in Trekh Nawa, Afghanistan in 2010. However, the new dawn in ODOAN reserves faith in the system and has trust over the rule-of-law; it does not endorse conflict operations. ODOAN believes that, ethical medical practice will prevail and professional hierarchy will be maintained.

It is a universal fact that, patient's desire to receive quality treatment can best be fulfilled by a qualified specialist. In fact, it is the rights of a patient to receive the best. The problem is; how will the patient know about the genuine practitioners. Awareness is the answer to ignorance. The ODOAN can play a key role in spreading the awareness using mass media or social media. 'MS Saga: A New Dawn' (MS refers to mobile suit) is a role-playing game for PlayStation. This game was designed to be accessible to general audience in 2005. If a video game could be accessible to general public, it is an irony that the essential quality health service is ignorant to the people.

Despite the desire and demand of quality orthodontic service, the specialists are struggling for respectable employment and optimal recognition in the society. The orthodontists' position will establish; when the specialists are abundant in number (supply-side), offer quality service to the people, and offer the service at reasonable costs. Orthodontists' place can never be replaced by any other; if they are better in knowledge, skill and attitude. Communication skill and updated technology are other factors which will bind the specialist practitioner to the patient. 'New Dawn' (or Intelsat 28) is the broadband communication satellite to Africa launched in 2011 , which opened the avenues of mass communication through technology.

In preserving the rights; the specialists should not forget their duties and responsibilities. While exercising the privileges of the specialists; those of the sub-ordinates should be maintained. The specialists should adhere to the ethical guidelines laid down by the authorities and exhibit the utmost professional behavior amicable to their altitude. They should meet the desired expectations of the patient and also perform the cases exclusive of the general practice. The members of the specialty society shall restrain from indulging in unprofessional activities that would generally be regarded as disgraceful by the professional society and that would hinder the professional unity.

We believe that a new dawn has arrived in ODOAN which brings strength, commitment and dedication to work for the association towards the rights and welfare of its fellow members. The specialty society will then verse a tuneful song 'new dawn' in harmony with the lawful and prosperous country. 